\title{
AS ORIGENS IDEOLÓGICAS DA LEI SMITH-HUGHES DE 1917 DOS ESTADOS UNIDOS DA AMÉRICA
}

\section{THE IDEOLOGICAL ORIGINS OF THE SMITH-HUGHES ACT OF 1917 IN THE UNITED STATES OF AMERICA}

\section{RESUMO}

Ana Lúcia Braz Dias ${ }^{1}$

Investigação sobre as origens ideológicas da educação vocacional estadunidense no início do século XX, buscando mapear os principais atores na aprovação da lei Smith-Hughes e seus interesses por meio de pesquisa bibliográfica. Como resultado, ficou claro que foi necessária, no processo que culminou com a aprovação da primeira lei que garantia financiamento federal à educação vocacional nos Estados Unidos, uma coligação de atores cuja cooperação seria bastante improvável em qualquer circunstância: movimentos de trabalhadores, educadores, industriais, agricultores. Em meio a tantos diferentes interesses e posicionamentos quanto à forma que a educação vocacional deveria ter e quanto aos propósitos que ela deveria servir, os grupos mais influentes conseguiram se unir em torno do desejo de racionalizar a formação para o trabalho sem atacar diretamente a estrutura de classes e o sistema capitalista. O resultado foi que questões sobre a natureza do trabalho e desigualdade forma transformadas em questões de educação e treinamento.

Palavras-Chave: Smith-Hughes. Dewey. Sindicatos. História da educação vocacional. Eficiência social.

\begin{abstract}
Investigation of the ideological origins of US vocational education in the early twentieth century, seeking to map the main agents involved in the approval of the Smith-Hughes law and its interests through bibliographic research. As a result, it was learned that in the process that culminated in the passage of the first law guaranteeing federal funding for vocational education in the United States, a coalition of actors was formed, whose cooperation would be quite improbable under all circumstances: workers, educators, industrial movements, farmers. In the midst of so many different interests and positions regarding the form that vocational education should take and the purposes it should serve, the most influential groups were able to unite around the desire to rationalize training for work without directly attacking the structure of classes and the capitalist system. The result that questions about the nature of work and inequality were turned into issues of education and training.
\end{abstract}

Keywords: Smith-Hughes. Dewey. Unions. History of vocational eduation. Social efficiency.

\section{INTRODUÇÃO}

Este ano marca o centenário da aprovação da lei Smith-Hughes nos Estados Unidos da América, que configurou o início da provisão de recursos federais para a educação vocacional naquele país. A lei foi assinada em 23 de fevereiro de 1917. Em 6 de abril daquele

\footnotetext{
${ }^{1}$ Doutora em Educação Matemática pela Indiana University, Professora do Departamento de Matemática da Central Michigan University. E-mail: dias1al@ cmich.edu. 
mesmo ano os Estados Unidos entraram militarmente na Primeira Guerra Mundial, apesar de já terem estado envolvidos no conflito anteriormente por meio de fornecimento de armamentos. Em novembro culminava a revolução bolchevique na Rússia, uma das maiores vitórias da classe operária na história. Com um contexto tão marcadamente conturbado e cheio de acontecimentos importantes, como estaria a lei Smith-Hughes situada? Estaria ela relacionada a movimentos operários nos Estados Unidos? Sendo obviamente tão anterior à guerra fria, será que o contexto comunista tinha alguma influência no que estava acontecendo nos Estados Unidos, ou será que, estando situada em um regime capitalista, a luta por uma educação para o trabalho naquele contexto não tinha relação alguma com o que estava ocorrendo na Rússia? O ensejo deste Encontro Internacional Trabalho e Perspectiva de Formação dos Trabalhadores e sua temática Ecos de 1917: Educação para Emancipação Humana, Formação para o Trabalho e as Lutas Sociais fez-me levantar essas questões.

Apesar de ser comum na literatura a apresentação da lei Smith-Hughes como o início da educação vocacional nos Estados Unidos, as perguntas acima não são comumente abordadas nos livros didáticos de história da educação vocacional. Portanto propus-me neste ensaio a procurar respostas na bibliografia mais abrangente e de áreas afins.

Essas perguntas talvez sejam "não-questões" para historiadores ou alunos de história, mas entre educadores talvez esse quadro não se mostre tão claro, como me faz ver a reação de alguns colegas à minha ideia de apresentar, em um encontro acadêmico de temática soviética, um trabalho sobre o contexto estadunidense.

Mais que uma simples contextualização histórica, essa investigação é um exercício em compreender uma legislação por meio dos debates que a ela deram origem, indo além do que fica evidente à primeira vista do aspecto literal da lei e buscando compreender o mosaico ideológico que fundamentava aqueles debates. É, portanto, relevante ao contexto atual como abordagem e como fundamentação para o entendimento dos debates atuais sobre educação para o trabalho.

\section{O MOVIMENTO DA EDUCAÇÃO VOCACIONAL NO INÍCIO DO SÉCULO XX}

Costuma-se usar o termo "movimento da educação vocacional" ou "movimento da educação industrial" nos Estados Unidos para designar a pressão exercida por diversos grupos no período de 1906 a 1917 para conseguir apoio federal à educação vocacional naquele país. O movimento começou com dois eventos: o relatório da Comissão para Educação Vocacional do governador de Massachusetts e a fundaçào da Sociedade Nacional para a Promoção da 
Educação Industrial (National Society for the Promotion of Industrial Education - NSPIE). O movimento culminou com a aprovação da lei Smith-Hughes em 1917, que foi possível por causa do apoio coordenado de grupos de interesse tão diversos quanto a Associação Nacional de Manufatores (National Association of Manufacturers - NAM), a Câmara de Comércio, a Federação Americana do Trabalho (American Federation of Labor - AFL) e organizações de agricultores, entre outros. (WIRTH, 1974)

Wirth coloca que:

Ao olhar para o conjunto de forças em contenção no movimento de educação vocacional (1900-1917), podemos ver não somente como a tecnologia age como pressão para mudança institucional. Podemos ver algo sobre o conflito das duas Americas que nós, de fato, nos tornamos nos cem anos após a guerra civil: a America que define suas aspirações em termos do impulso cego em direção ao aumento de bens materiais, e aquela outra America que Paul Goodman descreveu como o "experimento libertário, pluralista e populista".

Para ser franco e simples, a escolha então e agora é se a escola deve ser tornar serva das necessidades de eficiência tecnocrática, ou se ela pode agir para ajudar os homens a humanizar a vida sob a tecnologia. (WIRTH, 1974, p. 169)

A proposta do movimento era substituir o currículo geral por cursos práticos, orientados para infundir a escola com um novo espírito de vocacionalismo (KANTOR, 1986). No entanto, os diferentes grupos que se involveram com o movimento tinham visões diferentes sobre como isto deveria acontecer.

Para Drost (1977), não há dúvidas de que a maioria dos estadunidenses acreditava, então, que a escola deveria ser capaz de demonstrar sua utilidade, e que o jeito melhor de fazer isso seria focar em transmitir conhecimentos, habilidades e atitudes que pudessem ser aplicados a um emprego específico ou a um papel doméstico. Não há dúvidas entre os historiadores da educação de que essa fora uma mudança marcante na educação estadunidense no início do século XX. No entanto, de acordo com Kantor (1986) não há tanto consenso quanto aos objetivos reais de tal mudança.

\footnotetext{
“Os primeiros cronistas - muitas vezes eles mesmos participantes - aplaudiram a ascensão do vocacionalismo, vendo-o como um movimento liberal para democratizar o sistema educacional e expandir oportunidades profissionais para juventude da classe trabalhadora e imigrante. (...) Nas últimas duas décadas, no entanto, historiadores revisionistas têm pintado uma imagem muito diferente desses eventos. Educação vocacional, dizem eles, não foi produto de sentimentos democráticos, mas foi o resultado de pressão por parte de empresários e educadores de mentalidade eficientista interessados em usar a escola para controlar os trabalhadores e estabilizar a sociedade industrial corporativa que estava surgindo no início do século XX. O resultado, afirmam eles, foi um sistema escolar que socializava os jovens para seus novos papeis econômicos e os separava em nichos apropriados na divisão do trabalho capitalista que se expandia. (KANTOR, 1986, p. 402)
} 
Para Kantor (1986), esses estudos revisionistas reformularam nossa compreensão do desenvolvimento da educação americana. Acima de tudo, eles deixaram claro que a história da reforma educacional não foi automaticamente progressiva e que o surgimento da educação vocacional não pode ser separado da realidade de desigualdade de classe que caracterizou a sociedade americana do início do século XX. Kantor (1986) adverte, no entanto, que a imagem do controle social na literatura revisionista também traz seus próprios riscos de distorção, pois o movimento vocacional era muito mais diversificado em seus círculos eleitorais e interesses do que a perspectiva revisionista sugere. Ele elabora que não só empresários, apologistas corporativos e educadores orientados para a eficiência, mas também líderes sindicais, reformistas liberais e intelectuais radicais se juntaram à campanha para vocacionalizar as escolas. Esses grupos diferiam frequentemente uns dos outros em relação aos objetivos e à organização do ensino profissional. No entanto, todos concordaram que a revolução industrial que transformava a economia americana significava que a escola devia assumir novas responsabilidades vocacionais.

Kantor (1986) se pergunta por que a educação vocacional atraiu tão amplo espectro de grupos, incluindo alguns que geralmente se consideravam adversários. Ele conclui que o que uniu todos esses grupos era um desejo de tornar a sociedade existente melhor sem atacar diretamente a propriedade privada ou a estrutura da classe. Assim, mesmo que os reformadores muitas vezes discordassem uns dos outros sobre políticas vocacionais, suas disputas raramente levantavam questões sobre quem controlava a economia ou para que fins. Ao contrário, todos eles achavam que os conflitos e problemas surgidos da industrialização do trabalho deveriam ser resolvidos por um melhor treinamento nas escolas.

\section{POSIÇÕES IDEOLÓGICAS E SEUS REPRESENTANTES}

Os significados atribuídos ao termo ideologia na literatura acadêmica são bem variados. O sentido do termo sofreu mudanças historicamente e varia de autor para autor em um mesmo período. Enquanto é comum para algumas interpretações ortodoxas de Marx usar o termo estritamente para uma forma de consciência falsa, que, como uma camera obscura, inverte a realidade, outros consideram ideologia como qualquer sistema de crenças que ajudam a pessoas a fazer sentido de sua realidade. Evitando uma posição onde qualquer crença é ideológica, aqui uso o termo no sentido apontado por Apple (1990), que é o de que ideologia é um conjunto de crenças que justifica a ação de um grupo ou indivíduo para obter ou manter aceitação social daquela ação, estando ou não esses atores cientes de que o estejam fazendo. Ou 
seja, o termo ideologia se aplica quando um conjunto de ideias é usado em questões de legitimação de poder e em conflitos sociais.

A seguir, ofereço uma breve introdução aos principais indivíduos ou grupos envolvidos no movimento vocacional que culminou com a aprovação da lei Smith-Hughes e procuro apontar as justificativas que ofereciam em sua luta pelo apoio federal a um ou outro tipo de formação para o trabalho.

\subsection{Associação Nacional de Manufatores - NAM}

De todos os defensores da educação vocacional, um dos primeiros foi a NAM. Logo que formada, em 1895, como consequência da depressão de 1893, a NAM propagou a ideia de que a causa dos problemas havia sido uma hiperproduçao, e que a única saída seria ultrapassar as fronteiras do mercado doméstico e batalhar pelos mercados asiático e latinoamericano. No entanto, para isso, teriam que competir com a Alemanha, grande potência no mercado internacional. A associação logo enviou emissários àquele país para investigar a fonte de seu sucesso. Confrontados com o sistema dual de ensino, no qual havia um forte sistema de treinamento especializado paralelo ao ensino geral, a NAM começou a argumentar que os Estados Unidos deveriam seguir o exemplo da Alemanha, ou perderiam seu lugar no mercado internacional. (WIRTH, 1974)

A NAM ficou alarmada também com o crescimento da adesão sindical que seguiu a recuperação da depressão da década de 1890 e esperava que a educação vocacional erodisse o poder sindical no mercado de trabalho, fornecendo uma fonte alternativa de trabalhadores treinados. Eles acusaram os sindicatos de destruírem o aprendizado, envenenarem o relacionamento entre mestre e aprendiz e restringirem o ingresso a certas atividades, em detrimento de ambos grupos, trabalhadores e empregadores. Membros da NAM alegavam que a restrição sindical prejudicava os trabalhadores tanto quanto ou mais que os empregadores, porque interferia com o direito de todos os jovens de aprender um ofício. Era importante também para os membros da NAM ajustar os trabalhadores menos qualificados às demandas do trabalho rotineiro das fábricas. Eles estavam preocupados com o fato de que a expansão da indústria e a subdivisão de tarefas haviam contribuído para a agitação industrial. Os trabalhadores, que antes participavam da criação de um produto do início ao fim, agora eram responsáveis por serviços rotineiros e diferenciados. Isso não apenas diminuía a sensação de propósito e satisfação no trabalho, mas acabou com a possibilidade do velho sistema de treinamento por meio da relação mestre-aprendiz. Empresários passaram então a ter a esperança 
de que trabalhadores melhor treinados pudessem se tornar mais estáveis e cooperativos, porque entenderiam seu papel no sistema industrial como um todo. (KANTOR, 1986; HILLISON, 1995; HYSLOP-MARGISON, 2000)

O tipo de escola pregado pela NAM para a educação vocacional variou em diferentes épocas, e diferentes argumentos foram oferecidos para embasar suas recomendações. Inicialmente, oficiais da NAM não acreditavam que seus objetivos para a educação vocacional pudessem ser alcançados nas escolas públicas. Achavam que seus métodos seriam muito livrescos, e que estariam sujeitos a ideologias dos professores e à influência de sindicatos de trabalhadores. Pensavam em exercer sua influência por meio de escolas de ofícios particulares e de tempo integral que começaram a aparecer nos Estados Unidos ao final do século XIX. Estes recebiam gordas doações de empresários. No entanto, mais tarde esse entusiasmo foi-se esmorecendo, pois jovens de 14 anos tinham que abandonar a escola para trabalhar, e não poderiam nunca se dedicar a uma escola de tempo integral.

Passaram então a propor escolas de continuação (continuation schools). Espelhadas em um modelo alemão, essas escolas ofereceriam 8 horas semanais de estudos gerais e profissionais a jovens de 14 a 16 anos que houvessem deixado a escola pública para trabalhar. Oficiais da NAM alegavam que essas escolas forneceriam formação profissional necessária para aqueles que nunca iriam para uma escola de ofícios, por correlacionar de perto a instrução escolar com o emprego real.. Além disso, argumentavam eles, como os jovens receberiam sua experiência prática no próprio local de trabalho, essas escolas não teriam necessidade de comprar equipamentos elaborados. Assim, eles poderiam fornecer a instrução vocacional necessária muito mais barato do que as escolas de ofícios jamais iriam ser capazes de fazer. (KANTOR, 1986)

Uma alternativa que atraiu empresários foi criar seus próprios programas para treinar seus funcionários. Em 1913, representantes de 37 fabricantes e ferrovias formaram a Associação Nacional de Escolas de Cooperação (National Association of Corporation Schools - NACS) para compartilhar informações sobre programas de educação no trabalho e promover um interesse em treinamento corporativo.

Essas escolas corporativas eram atraentes para empresários pelas mesmas razões que as escolas de ofícios: elas poderiam ser voltadas para necessidades industriais específicas e poderiam ser mantidas livres de interferências de organizações trabalhistas e sindicatos. Esse era um dos principais motivos pelos quais empresários duvidavam do valor da educação vocacional na escola pública. Um partidário do treinamento corporativo, por exemplo, 
ridicularizou a ideia de formar jovens para empregos industriais nas escolas públicas, rotulando a ideia como "o sonho do professor e do reformador social profissional ou diletante". O sistema escolar americano, em sua opinião, era "politicamente armado" e sujeito à pressão externa das organizações trabalhistas. (National Association of Corporation Schools, citada em KANTOR, 1986, p. 408).

No entanto, poucos empresários da NAM podiam criar suas próprias escolas para formar seus funcionários. Mesmo gigantes industriais, como a General Electric e a Westinghouse, nunca poderiam ter certeza de que seu investimento em treinamento valeria a pena, uma vez que os trabalhadores sempre poderiam mudar de emprego uma vez treinados. Assim, enquanto muitos grandes empresários continuaram a almejar por uma educação corporativa, eles raramente dependiam exclusivamente desses programas privados para atender sua demanda por funcionários treinados. Ansiosos por terem um fornecimento constante de mão-de-obra com habilidades e hábitos industriais gerais, eles também solicitavam que as escolas públicas adaptassem seus currículos às necessidades industriais e se juntaram a outros empresários no NAM no movimento em prol do ensino vocacional nas escolas públicas.

\subsection{Sindicatos de Trabalhadores}

\subsubsection{Federação Americana do Trabalho - AFL}

A adesão sindical nos Estados Unidos passou de meio milhão em 1897 para quase dois milhões em 1902 (KANTOR, 1986). Até a virada do século, o trabalho organizado pouco tomou parte nas discussões sobre educação vocacional (BOWLES, GINTIS, 1976). É compreensível que os movimentos sindicais fossem relutantes em aderir a um movimento com tão fortes raízes antisindicais, como o descrito na seção anterior.

A oposição, apesar de uma posição de minoria, era vociferante. O secretário do
sindicato de fabricantes de charuto no. 144 chamou essas escolas de "incubadoras de
furadores de greves" e o secretario da Twist and Warp Lace Makers Association
avisou que a educação vocacional "... ia ser uma praga ao invés de uma benção
colocando à disposição de todo capitalista investido em baixar salários ao mínimo
ponto um número ilimitado de capacitados sem trabalho, para substituir aqueles que
pudessem resistir a sua tirania." A defesa flagrantemente antisindicalista da educação
vocacional pela N.A.M. enrigeceu a oposição trabalhista e, à virada do século, Samuel
Gompers e a AFL tinham tomado uma posição firme contra o movimento. (BOWLES;
GINTIS, 1976, p. 193)

Muitos líderes sindicais desconfiavam da influência de empresários nas escolas públicas e acreditavam que os professores eram hostis ao trabalho organizado e às crianças da classe trabalhadora. Mas, à medida em que o movimento vocacional se ampliava, a oposição sindical à educação vocacional começou a se desfazer e a liderança da AFL adotou uma posição 
mais favorável a ela. Em 1907, o presidente da AFL se juntou à NSPIE e em 1910 a AFL passou a apoiar publicamente o movimento pela educação vocacional. (KANTOR, 1986)

Os motivos responsáveis pela mudança de posição da AFL foram vários. Por um lado, os trabalhadores concordavam com os empresários com relação ao fato de o sistema de mentores e aprendizes estar ultrapassado e não ser suficiente para a formação pretendida. Por outro lado, líderes sindicais apontavam que os métodos das escolas eram enfadonhos, e que os jovens tinham aspirações práticas que não eram contempladas na escola. Finalmente, os líderes sindicais reconheciam que o movimento vocacional estava crescendo e temiam que a influência excessiva de empresários fosse prejudicial ao trabalho organizado. Viram-se então compelidos a agir para contrariar a dominância empresarial. Eles acreditavam que a participação sindical poderia mitigar os efeitos nocivos da iniciativa particular ao insistir no patrocínio público e não privado do ensino vocacional, na participação sindical na tomada de decisões educacionais e na prevenção da extrema especialização em treinamento comercial. (KANTOR, 1986; WIRTH, 1972)

A AFL era uma associação modestamente elitista, pois consistia de membros empregados em ocupações da "aristocracia artesã". Então seu principal interesse, de acordo com Hillison (1995) era garantir oportunidades similares para os filhos de seus membros. Se a nova geração saísse da escola antes de terminar o nível médio, provavelmente não conseguiriam empregos especializados. Por outro lado, se fosse para a universidade provavelmente entrariam para carreiras profissionais ou intelectuais, dois grupos que os artesãos não valorizavam. Então seu objetivo passou a ser inserir um elemento vocacional na escola pública de nível médio como forma de manter seus filhos interessados na escola, e para que estes recebessem um tipo de educação que lhes fosse útil.

\subsubsection{Trabalhadores Industriais do Mundo - IWW}

O Trabalhadores Industriais do Mundo (Industrial Workers of the World - IWW), cujos membros são comumente conhecidos como "Wobblies", é um sindicato internacional que foi fundado em 1905 em Chicago, Illinois, nos Estados Unidos da América. A união combina o sindicalismo geral com o sindicalismo industrial, uma vez que é uma união geral cujos membros estão mais organizados na indústria de seu emprego. A filosofia e as táticas da IWW são descritas como "sindicalismo industrial revolucionário", com vínculos com os movimentos trabalhistas socialistas e anarquistas. Sua maior notoriedade e influência ocorreram nos anos de 1905 a 1920, quando a organização foi duramente reprimida pelo Departamento de Justiça dos 
Estados Unidos. Note-se que a IWW ressurgiu décadas depois, nos anos de 1960, e no século XXI tem experimentado um importante crescimento. (WIKEPEDIA, 2004)

Fundada em 1905 como uma alternativa radical à Federação Americana do Trabalho
(AFL), a IWW adotou simultaneamente ação coletiva através de sindicatos
industriais, bem como noções anarquistas de liberdade e hostilidade ao governo. A
IWW defendeu a derrubada do capitalismo, mas não pensou que o socialismo poderia
ser alcançado através do processo político, em vez disso, concentrando sua energia
onde os trabalhadores detiveram seu maior poder, no trabalho. Esses homens e
mulheres acreditavam que aqueles que trabalharam nas docas, debaixo da crosta
terrestre, nas florestas e nos moinhos, mereciam controlar a riqueza, e não eram
tímidos em compartilhar sua visão. Centenas de milhares se juntaram à organização
de esquerda orgulhosamente militante e extravagante, e milhões de pessoas foram
influenciadas por ela, enquanto os empregadores e funcionários governamentais
visavam a sua destruição. (COLE, 2007, p. 2 )

Devido a vários fatores, a adesão à IWW diminuiu drasticamente na década de 1920. Houve conflitos com outros grupos trabalhistas, em particular a Federação Americana do Trabalho (AFL), que considerava a IWW como radical demais, enquanto a IWW considerava a AFL como conservadora. A adesão também diminuiu devido às repressões governamentais sobre grupos radicais, anarquistas e socialistas durante o chamado Primeiro Susto Vermelho (First Red Scare), após a Primeira Guerra Mundial. No entanto, o fator mais decisivo no declínio da participação e influência da IWW foi um cisma na organização, em 1924, a partir do qual a IWW nunca se recuperou completamente. A IWW promove o conceito de "One Big Union" (Um Grande Sindicato) e afirma que todos os trabalhadores devem estar unidos como uma classe social para suplantar o capitalismo e o trabalho assalariado com a democracia industrial. Eles são conhecidos pelo modelo Wobbly Shop de democracia no local de trabalho, no qual os trabalhadores escolhem seus gestores e outras formas de autogestão são implementadas. A adesão à IWW não exige que alguém trabalhe em um local representado, nem exclui a adesão a outro sindicato (WIKEPEDIA, 2004).

A IWW foi fundada por socialistas, anarquistas, marxistas e sindicalistas radicais de todos os Estados Unidos, principalmente membros do Partido Socialista da América e do Partido Socialista Trabalhista, que se reuniram em uma convenção em Chicago em junho de 1905. Os fundadores se opunham fortemente às políticas da Federação Americana do Trabalho (AFL). O principal ponto de crítica da IWW à AFL era a aceitação do capitalismo, por parte dessa última, e sua recusa em incluir trabalhadores não qualificados em sindicatos de artesãos.

Em particular, a IWW foi fundada por causa da crença entre muitos sindicalistas socialistas, anarquistas, marxistas e radicais de que a AFL não só havia falhado na organização efetiva da classe trabalhadora dos EUA, mas que, ao invés de unidade, estava causando 
separação dentro de grupos de trabalhadores, por organizá-los de acordo com uma visão estreita de diferentes classes de artesãos. Os Wobblies acreditavam que todos os trabalhadores deveriam se organizar como uma classe, com o objetivo de promover a solidariedade entre os trabalhadores na luta revolucionária para derrubar a classe patronal, uma filosofia que ainda se reflete no Preâmbulo da atual Constituição da IWW. (COLE, 2007)

Cole (2007) relata que Fred Thompson o historiador oficial da IWW, conclui, ao final de 1920, que dada a amarga luta interna do IWW a respeito do comunismo, estava claro que nada comparável à revolução bolchevique ocorreria na Europa Ocidental ou nos Estados Unidos. Cole relata também que Lênin chegara à mesma conclusão, e então ordenara que os comunistas se filiassem a movimentos trabalhistas convencionais em suas respectivas nações. Nos Estados Unidos, isso significaria se integrar à AFL. No entanto, a maioria sindicalistas, incluindo a IWW, opôs-se à nova política, porque acreditavam que a AFL nunca iria se aliar aos ideiais comunistas. (COLE, 2007)

Não foi possível encontrar referências sobre a visão da IWW sobre o movimento vocacionista, mas concluímos pela história da organização e seu antagonismo à AFL que a mesma não teria apoiado a Lei Smith-Hughes, o que evidencia ainda mais nosso argumento de que os ideais da lei eram antagônicos aos dos interesses da classe trabalhadora.

\subsection{Educadores}

\subsubsection{Adeptos do ideário da Eficiência Social}

Em 1905, William Bagley avançou a ideia de que, em nome da "eficiência social", a escola deveria treinar seus jovens em habilidades que eles pudessem usar no trabalho. W. W. Charters e Franklin Bobbitt eram adeptos de visões semelhantes, tendo inclusive se dedicado a listar quais seriam essas habilidades, e qual seria o melhor modo de ensiná-las. Mas foi David Snedden (1868-1951), que levou a ideia um passo "adiante": para ele, a escola deveria projetar o destino social e educacional de seus alunos. Além disso, Snedden foi provavelment o teórico mais prolífico dessa escola. (DROST, 1977)

Snedden abandonou uma cátedra na Teachers College da Columbia University para ser comissário de educação do governador Douglas, do estado de Massachussets. Ele nomeou seu colega e ex-aluno Charles Prosser como seu assistente. Em 1912 Prosser tornou-se Secretário Executivo da Sociedade Nacional para a Promoção da Educação Industrial (National Society for the Promotion of Industrial Education - NSPIE) e acabou sendo o primeiro redator da lei Smith-Hughes. 
Snedden e Prosser elaboraram o rationale tecnocrático que embasou o movimento vocacional com cunho eficientista. Eles eram a favor de uma filosofia social conservadora, dos princípios da psicologia behaviorista (estímulo-resposta) como metodologia de ensino, de um currículo formulado para atender as necessidades de indústria e de um sistema "dual" (escolas vocacionais e liberais em instituições separadas, com administrações próprias). (WIRTH, 1974)

Wirth afirma até que Snedden concordava com os darwinistas sociais na crença de que o capitalismo corporativo era o "instrumento cósmico para o progresso" e que ele "aceitava a proposição básica de que dos manufatores de que o que era bom para os negócios era bom para a América". (WIRTH, 1974, p. 171).

\subsubsection{Educadores progressistas}

O movimento progressista na educação estadunidense se estendeu da década de 1890 à década de 1930. Esse movimento foi alimentado por uma forte inquietação social decorrente da integração de massas de trabalhadores a um novo modelo econômico e social. Representa na história da educação dos Estados Unidos uma proposta radicalmente diferente de escola, que promovia a diversidade, a unidade entre escola e comunidade e uma pedagogia centrada na criança.

John Dewey (1859-1952) foi um dos principais proponentes do movimento progressista na educação. A concepção de escola de Dewey era completamente contrária à dos defensores da eficiência social. Era uma educação que ampliaria os horizontes dos alunos e lhes proporcionaria as ferramentas para interpretar e alterar seu mundo. Por isso Dewey trabalhou muito para tentar garantir que o projeto Smith-Hughes não se tornasse contrário à visão que ele construiu da relação entre educação e trabalho.

Dewey estava escrevendo sobre o assunto da educação industrial já à abertura do século; ele aumentou seus esforços quando as legislações estaduais e federais para a educação vocacional estavam sendo preparadas antes de 1917. A estratégia de Dewey era descrever as possibilidades de usos educacionais imaginativos para o industrialismo e contrastar esses com as tendências erradas do movimento para a educação vocacional. (WIRTH, 1972, p. 69)

A inquietude de Dewey com relação a Smith-Hughes já vinha de suas críticas a propostas anteriores de legislaturas estaduais para programas vocacionais. Dewey fez comentários sobre esses desenvolvimentos em um artigo intitulado A Policy of Industrial Education (DEWEY, 1914) and Industrial Education - A Wrong Kind (DEWEY, 1915). Lá ele critica a configuração da Commission on National Aid to Vocational Education (Comissão de Auxílio Nacional à Educação Vocacional): 
A formação pelo Congresso de uma Comissão de Auxílio Nacional à Educação Vocacional, composta por dois senadores, dois representantes e cinco leigos, refletem o sistema tradicional e a sensação de necessidade de sua mudança. Nenhum dos cinco membros leigos é um educador profissional. (...) A proposta é característica da nossa tradição. Estamos longe do dia em que a direção e supervisão da educação de apoio público será uma função pública. (DEWEY, 1914, p. 53-54)

E continuou:

[A] ausência de educadores da Comissão Nacional de Apoio à Educação Vocacional tem um significado peculiar. Os educadores profissionais não são isentos de culpa, devido à sua indisposição para enfrentar a questão da reorganização educacional. Mas deixar os educadores fora da discussão de um problema educacional é uma medida curiosa. Eles terão que se encarregar de uma grande parte da execução de qualquer plano que possa ser adotado. Se eles não se pode ter confiança neles para ter uma participação responsável na elaboração do plano, as chances de execução bem sucedida do plano por parte deles são realmente pequenas. (DEWEY, 1914, p. 56).

Para Dewey (1914), em primeiro lugar o objetivo da educação industrial pública deveria ser manter crianças sob a tutela da escola por mais tempo. Sobre as experiências de usar a indústria para fins educativos em Chicago, Gary e Cincinatti, Dewey (1914) explicou que não se tratava de usar a escola como preliminares de fábricas a custo das finanças públicas, mas sim de pegar emprestado da indústria os recursos e motivos que fariam a educação mais atraente e de maior alcance. Em segundo lugar, Dewey argumentou, não adiantaria uma preparação para trabalhos específicos, pois estes mudariam rapidamente com o surgimento de novas tecnologias. O necessário seria desenvolver iniciativa e recursos pessoais de inteligência. "As mesmas forças que tornaram obsoleto o modelo mestre-aprendiz torna fútil uma imitação escolástica do mesmo". (DEWEY, 1914, p. 56).

Dewey alertou para o fato de que o mundo dos negócios estava se infiltrando na educação e para a tendência de autores de políticas educacionais quererem subordinar a escola aos interesses da indústria e dos empregadores. Para ele, isso refletia uma visão de educação aristotélica, que pregava "educação" para as classes pensantes e "treinamento" para os trabalhadores braçais. Ele se esforçava para evitar que a legislação estabelecesse sistemas separados para os filhos da classe trabalhadora e para aqueles das classes dominantes. Escreveu amplamente também contra a visão de escola dos proponentes da Eficiência Social, que, como vimos na seção anterior, argumentava que a escola devia preparar para tarefas ou ocupações específicas. Dewey (1914) mantinha uma visão mais ampla do valor formativo do trabalho, e enfatizava que jovens de todas as origens se beneficiariam em aprender por meio do trabalho. Argumentava também que o poder de escolha dos jovens para mudar de ocupação deveria ser possibilitado, não afunilando suas possibilidades vocacionais com treinamentos para tarefas específicas. 
Snedden (1977), que foi colega de Dewey na Columbia University, mostrou-se publicamente indignado com o posicionamento de Dewey, escrevendo em uma carta de duas páginas ao The New Republic que havia ficado surpreso com a oposição de Dewey (SNEDDEN; DEWEY, 1977). Disse ele que nunca poderia pensar que um educador que ele tinha em tão alta estima pudesse compreender tão mal as vantagens das mudanças que a Eficiência Social propunha, bem como os motivos por trás de suas propostas. Dewey simplesmente respondeu que:

O tipo de educação vocacional em que eu estou interessado não é um que vá "adaptar"
trabalhadores ao regime industrial existente; eu não estou suficientemente apaixonado
pelo regime para isso. Parece-me que a tarefa de todos os que não são simplesmente
servidores educacionais é resistir a todo movimento nessa direção e lutar por um tipo
de educação vocacional que vá primeiramente alterar o sistema industrial existent e
ultimamente transformá-lo". (SNEDDEN; DEWEY, 1977, p. 39).

Para Dewey (1914) o século vinte seria o teste de como os estadunidenses reagiriam ao tecnologismo emergente. Para ele havia possibilidade de caírem em um industrialismo mecânico ou de conseguirem domar o industrialismo, subjugando-o em prol dos interesses humanos e dotando-o de alma.

Vale ressaltar, pelo tema desta conferência, que as concepções de Dewey (1914) acabaram por ter grande influência na pedagogia soviética após esse período.

A principal atração da Rússia para Dewey era o quadro de educadores progressistas então no auge de sua influência na URSS. Ele admirava muito educadores soviéticos, como Stanislav T. Shatskii, que faziam parte de uma comunidade de pensadores progressistas que atravessam não apenas o Oceano Atlântico, mas também o Mar Báltico ou, talvez, o Estreito de Bering. (ENGERMAN, 2006, p. 39)

Reciprocamente, Dewey havia influenciado os progressistas soviéticos:

Os educadores progressistas atuaram na Rússia a partir da virada do século, inspirados por seus compatriotas (especialmente Leo Tolstoy), bem como ocidentais como Dewey. (...)

Em 1910, Shatskii tinha descoberto a filosofia e a teoria educacional de John Dewey, talvez auxiliado pela aparição da primeira edição russa de Escola e Sociedade três anos antes. Durante suas viagens europeias nos anos seguintes, ele procurou uma variedade de experiências educacionais progressistas, especialmente as escolas de trabalho. Apesar de nunca ter atravessado o Atlântico, Shatskii concluiu que os Estados Unidos contribuíram com "muito do que era edificante e valioso" tanto em pedagogia como em filosofia. (ENGERMAN, 2006, pp. 39-40)

\section{O QUE PREVALECEU NA LEI}

Enquanto que na maioria dos aspetos a legislação final refletiu as intenções da NAM, ela não era exatamente o que eles esperavam. A lei Smith-Hughes estipulava que o apoio se restringiria a alunos maiores de 14 anos, o que ia contra o que queriam os empregadores. Os 
sindicalistas e progressistas conseguiram também impedir a formação de um sistema dual como o da Alemanha. Com o passar dos anos ficou claro que o legado da lei não seria a criação de um sistema de tracking, mas a infusão do vocacionalismo nas escolas públicas de nível médio. (BOWLES; GINTIS, 1976)

A lei aprovada regulamentou o repasse de financiamentos para treinamento vocacional nas áreas de indústria e agricultura, mas deixou de lado treinamento para o comércio e outros que já ocorriam em algumas escolas. No geral, no entanto, foi importante por institucionalizar a ideia de que a preparação para o trabalho era uma das funções da educação pública de nível secundário naquele país. Possibilitou-se assim focar discussões subsequentes em como a escola faria isso, isto é, em questões pedagógicas. A questão sobre se era ou não papel do governo federal alocar provisões para a educação para o trabalho dava-se por resolvida.

Apesar desse aspecto positivo deste acontecimento, por outro lado podemos nos juntar a autores como Bowles and Gintis (1976) e Kantor (1986) e argumentar que essa ligação conceitual de educação e trabalho reforçou a crença tradicional estadunidense de que sucesso ou fracasso ocupacional é resultado do esforço individual, não da desigualdade de oportunidades no sistema capitalista.

\section{CONSIDERAÇÕES FINAIS}

Seguindo o argumento de Kantor (1986) concluímos que, em meio a tantos diferentes interesses e posicionamentos quanto à forma que a educação vocacional deveria ter e quanto aos propósitos que ela deveria servir, os grupos mais influentes conseguiram se unir em torno do desejo de racionalizar o funcionamento da economia sem atacar diretamente a propriedade privada ou a estrutura de classe. O resultado foi transformar questões sobre a natureza do trabalho e a desigualdade em questões de socialização e treinamento.

Nessa mesma linha podemos argumentar que, quando confrontadas com as subsequentes crises de desemprego e a moral industrial declinante, as pessoas podem ter sido levadas, por causa deste movimento de associação, a serem mais inclinadas a procurar soluções na educação, ao invés de direcionar esforços para intervenções mais diretas no mercado de trabalho e no local de trabalho.

\section{REFERÊNCIAS}

APPLE, M. W. Ideology and curriculum. New York: Routledge, 1990. 
BOWLES, S.; GINTIS, H. Schooling in capitalist America. New York: Basic Books, 1976.

COLE, $\mathrm{P}$. Wobblies on the waterfront : interracial unionism in progressive-era

Philadelphia. Baltimore: University of Illinois Press, 2007.

DEWEY, J. Some dangers in the present movement for industrial education. Child labor bulletin, v. 1, n. 4, p. 69-74, 1913.

A policy of industrial education. New republic, v. 1, n. 11-12, 1914.

Industrial education - a wrong kind. New republic, v. 2, p. 73-74, 1915.

The need of an industrial education in an industrial democracy. Manual training and vocational education, v. 17, p. 409-414, 1916.

DEWEY, J. C. On Industrial Education. Curriculum Inquiry, v. 7, n. 1, p. 53-60, 1977.

DROST, W. H. Social efficiency reexamined: the Dewey-Snedden controversy. Curriculum inquiry, v. 7, n. 1, p. 19-32, 1977.

ENGERMAN, D. C. John Dewey and the Soviet Union: pragmatism meets revolution. Modern intellectual history, v. 3, n. 1, p. 33-63, 2006.

HILLISON, J. The coalition that supported the Smith-Hughes Act or a case for strange bedfellows. Journal of vocational and technical education, v. 11, n. 2, p. 4-11, 1995.

HYSLOP-MARGISON, E. J. An assessment of the historical arguments in vocational education reform. Journal of career and technical education, v. 17, n. 1, p. 23-30, 2000.

KANTOR, H. Work, education, and vocational reform: the ideological origins of vocational education, 1890-1920. American journal of education, v. 94, n. 4, p. 401-426, 1986.

SNEDDEN, D. Fundamental distinctions between liberal and vocational education.

Curriculum Inquiry, v. 7, n. 1, p. 41-52, 1977.

SNEDDEN, D.; DEWEY, J. Two communications. Curriculum Inquiry, v. 7, n. 1, p. 33-37, 1977.

WIKIPEDIA. Industrial Workers of the World, 2004. Disponível em: < https://en.wikipedia.org/wiki/Industrial_Workers_of_the_World>. Acesso em 25 de outubro de 2017.

WIRTH, A. G. John Dewey's philosophical opposition to Smith-Hughes type vocational eduation. Educational theory, v. 22, n. 1, p. 69-77, 1972.

Philosophical issues in the vocational-liberal studies controversy (1900-1917): John Dewey vs. the social efficiency philosophers. Studies in philosophy and education, v. 8, n. 3, p. 169-182, 1974. 